\title{
Spectroscopic investigation of green synthesized ZnS nanoparticles encapsulated by sodium carboxy methyl cellulose
}

\author{
B. Lalitha Devi ${ }^{1,2} \cdot$ K. Mohan Rao ${ }^{1} \cdot$ D. Ramananda ${ }^{2}$
}

Received: 24 June 2020 / Accepted: 23 October 2020 / Published online: 6 November 2020

(c) The Author(s) 2020

\begin{abstract}
In this article, the capping action of Sodium carboxymethyl cellulose (NaCMC) on $\mathrm{ZnS}$ nanoparticles synthesized by microwave-assisted method is reported. The X-ray diffraction and electron diffraction studies corroborated nanocrystalline nature of cubic ZnS. Discontinuous cluster growth of particles was implied by optical absorption studies. This was reflected in transmission electron microscope images. Fourier-transform infrared studies confirmed NaCMC capping on the surface of $\mathrm{ZnS}$ nanoparticles. Effective encapsulation of $\mathrm{ZnS}$ nanoparticles by $\mathrm{NaCMC}$ was further supported by Raman scattering, thermal studies and photoluminescence studies. Surface modification of $\mathrm{ZnS}$ nanoparticles with $\mathrm{NaCMC}$ appear to be suitable for specific biomedical applications due to the nontoxicity of $\mathrm{ZnS}$ and NaCMC.
\end{abstract}

Keywords ZnS nanoparticles $\cdot$ Biopolymer $\cdot$ Microwave irradiation $\cdot$ Optical properties $\cdot$ Thermal properties

\section{Introduction}

ZnS belongs to II-VI semiconductors with a wide band gap of $3.68 \mathrm{eV}$ for sphalerite bulk phase. In addition to its low production cost and non-toxicity, $\mathrm{ZnS}$ is a thermally and chemically stable compound possessing a high dielectric constant of 8.7 [1]. Consequently, nanostructured $\mathrm{ZnS}$ finds itself in various fields such as super capacitors [2], solar energy applications [3], optical devices such as LED [4], biomedical applications [5][5] and luminescent display systems [7]. However, the nanosized $\mathrm{ZnS}$ particles are highly unstable and tend to agglomerate due to the surface effects of smallness in size. Therefore, confining the growth of nanoparticles (NPs) and providing surface passivation are of prime importance in the nanoparticle research. Biodegradable biopolymers offer an excellent opportunity in this direction.

Among naturally occurring biopolymers cellulose is most abundant one. Its derivatives have several advantages

K. Mohan Rao

kmohan.rao@manipal.edu

1 Department of Physics, Manipal Institute of Technology, Manipal Academy of Higher Education, Manipal, Karnataka, India 576104

2 Department of Physics, Bhandarkars' Arts and Science College, Kundapura, Karnataka, India 576201 such as recyclability, high viscosity, nontoxicity, biodegradability and cost effectiveness [8]. Sodium carboxy methyl cellulose $(\mathrm{NaCMC})$ is a water-soluble cellulose derivative with carboxy methyl groups attached to some of hydroxyl groups of glucopyranose monomers of cellulose backbone. $\mathrm{NaCMC}$ has received ample scientific attention, due to its polyelectrolyte character [9]. In view of its high transparency, good film-forming property, large mechanical strength, non-toxicity and biodegradability, it is found suitable for applications such as medicine, flocculating agent, chelating agent, emulsifier, thickening agent, water-retaining agent, sizing agent, and film-forming material [10-12]. Recent reports on $\mathrm{NaCMC}$ reveal that it works as a stabilizer in the preparation of certain semiconducting nanosized materials like $\mathrm{PbO}$ nanoparticles [13], $\mathrm{ZnO}$ [14], CdS [15], ZnS [16] and some magnetic nanoparticles such as $\mathrm{Fe}_{3} \mathrm{O}_{4}[17,18]$. Increase in light emission intensity has been reported in ref [16]. for NaCMC stabilisation of $\mathrm{ZnS}$ films.

A detailed study of preparation of NaCMC-capped $\mathrm{ZnS}$ NPs and characterization is relatively less explored. In the present work, we report a novel synthesis approach for $\mathrm{ZnS}$ nanostructures using microwave-assisted aqueous precipitation technique. Microwave heating is a simple, fast and efficient method in which material heating takes place by dielectric heating [19]. In conventional heating, an external thermal source heats the reaction medium by a conductive heating. But microwave irradiation (MWI) causes efficient 
in-core volumetric heating by direct coupling of microwave (MW) energy with the molecules of solvents, reagents, catalysts, etc. that are present in the reaction mixture [19]. The quick and uniform heating of reaction mixture in MW heating induces fast homogeneous nucleation that leads to the formation of uniform sized small NPs [19], while prolonged hydrothermal conventional heating leads to form bigger particles with better crystallinity [20]. MW-assisted synthesis leads to the formation of more defects in the synthesized powders [21]. In unpassivated MW-synthesized nanoparticles, such defects on surfaces diminish the luminous intensity in them [22]. MW-assisted chemical reactions performed at the optimized reaction temperatures are found to be cleaner, produce less biproducts compared to conventionally heated processes [23].

Zinc acetate dihydrate (ZA) and thioacetamide (TA) were used as precursors for $\mathrm{ZnS}$ and $\mathrm{NaCMC}$ was used as the capping agent. The synthesis involves non-toxic precursors, solvent (water) and energy-saving principles of microwave heating such that most of the principles of green chemistry are followed. Very good photoluminescence behavior was exhibited by the properly capped sample.

\section{Experimental}

\subsection{Chemicals}

Zinc acetate dihydrate $\left.\left[\mathrm{Zn}\left(\mathrm{CH}_{3} \mathrm{COO}\right)_{2} \cdot 2 \mathrm{H}_{2} \mathrm{O}\right)\right]$, thioacetamide $\left(\mathrm{CH}_{3} \mathrm{CSNH}_{2}\right)$ and sodium carboxy methyl cellulose (NaCMC) were purchased from Alfa Aesar (Germany). All chemical reagents were of pure analytical grade and used without further purification. Double distilled (DD) water was used as solvent.

\subsection{Synthesis of samples}

The synthesis procedure followed in the present work is similar to that explained in ref [24]. and [4] with certain modifications. About $0.025 \mathrm{~g}$ of $\mathrm{NaCMC}$ was dissolved in DD water and aged for $24 \mathrm{~h}$. To $0.15 \mathrm{M}$ zinc acetate aqueous solution, NaCMC solution was added and mixed well by stirring. Thioacetamide (TA) solution at a concentration of $0.27 \mathrm{M}$ in water was added to this. Total volume of the mixture was maintained to be $100 \mathrm{ml}$. The mixture was subjected to microwave irradiation in a domestic microwave oven (LG model: MS-2049UW of 20 L capacity operating at frequency $2.45 \mathrm{GHz}$ ) for predetermined $6 \mathrm{~min}$. The reaction was evidenced by a change in the color from clear to milky white. After cooling, $\mathrm{ZnS}$ was separated from solution by centrifugation. Sample was dried and named as S1. Experiment was repeated for different amounts like 0.05, 0.075 and $0.1 \mathrm{wt} \%$ of $\mathrm{NaCMC}$ addition and samples were named as
S2, S3 and S4, respectively. At concentrations beyond 0.1 $\mathrm{wt} \%$, the solution was so viscous that collection of particles became difficult and the obtained sample was sticky. Pure sample of $\mathrm{ZnS}$ was also synthesized without the addition of $\mathrm{NaCMC}$ for comparison.

\subsection{Characterization}

X-ray diffraction (XRD) was carried out with Rigaku Miniflex $600 \mathrm{X}$-ray diffractometer with monochromatic copper- $\mathrm{K}_{\alpha}$ radiation of wavelength $1.5402 \AA$. TEM analyses were done by JOEL JEM 2100 high-resolution transmission electron microscope (HRTEM) and UV-Vis absorption studies were carried out using SHIMADZU - 1800PC spectrophotometer for the dilute dispersion of sample in DD water. The $\mathrm{ZnS}$ powders were dispersed in $\mathrm{KBr}$ pellets and FTIR spectra was obtained with NICOLET- 6700 spectrophotometer. Photoluminescence (PL) spectra were obtained with Hitachi F-7000 Fluorescence Spectrophotometer. Raman scattering experiments were performed using BRUKER RFS 27:Stand-alone FT-Raman Spectrometer. The thermal analysis was done using the thermal analysis instrument SDT Q600 V20.9 Build 20 in nitrogen atmosphere at a heating rate of $3^{\circ} \mathrm{K} / \mathrm{min}$ for pure $\mathrm{ZnS}, \mathrm{ZnS}$ $\mathrm{NaCMC}$ composite $\mathrm{S} 2$ and neat $\mathrm{NaCMC}$.

\section{Results and discussion}

\subsection{X-ray diffraction}

XRD patterns of $\mathrm{ZnS}-\mathrm{NaCMC}$ nanocomposites and pure $\mathrm{ZnS}$ are shown in Fig. 1. The diffraction peaks are observed for $2 \theta$ values at $28^{\circ}, 48^{\circ}$ and $57^{\circ}$. The peaks are identified to originate from (111), (220) and (311) planes of the zinc blende structure of ZnS (JCPDS No. 01-072-4841). No peaks for other phases or elements are observed showing high purity of samples and the broad diffraction peaks is an indication of the particles in the nanometer dimension. The average nanocrystallite size (D) is determined for the prominent peak (111) using Scherrer equation:

$D=\frac{0.9 \lambda}{\beta \cos \theta}$,

where $\lambda$ is wavelength of incident X-rays; $\theta$ is angle of diffraction, $\beta$ is full width at half maximum (FWHM) of Bragg peak. The NaCMC capped samples show slight increase in crystallite size compared to uncapped ZnS. Murugadoss et al. explained similar increase in crystallite size due to binding of surfactant on the $\mathrm{ZnS}$ nanoparticles [25]. But the nanocrystallites do not appear to change much in size with $\mathrm{NaCMC}$ concentrations. Interplanar separations $\left(\mathrm{d}_{\mathrm{hkl}}\right)$ 

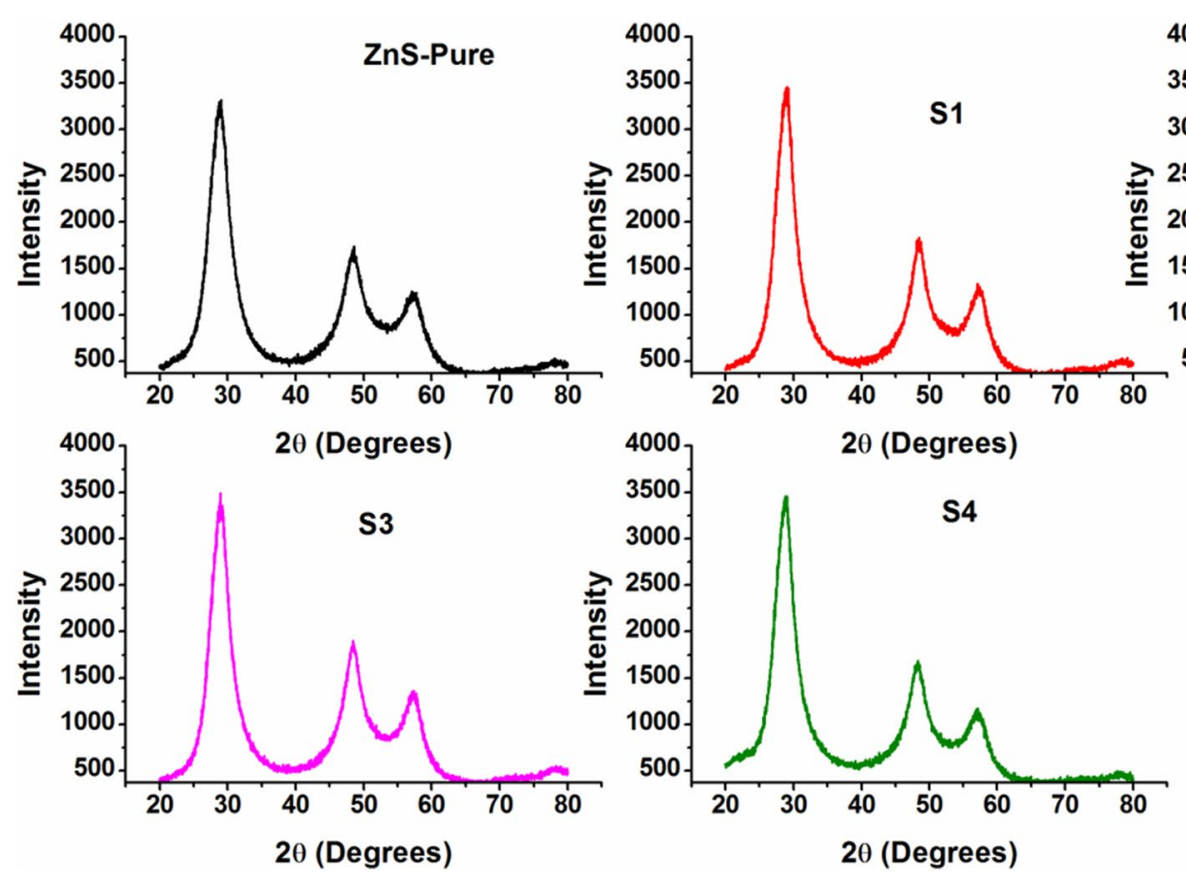

Fig. 1 XRD pattern for pure $\mathrm{ZnS}$ and $\mathrm{ZnS}-\mathrm{NaCMC}$ composite samples

Table 1 Comparison of different parameters for pure and NaCMCcapped $\mathrm{ZnS}$ nanocrystals

\begin{tabular}{llllll}
\hline Sample & $\begin{array}{l}\text { NaCMC } \\
\text { added } \\
(\% \text { wt. })\end{array}$ & $2 \theta\left(^{\circ}\right)$ & $\begin{array}{l}\text { Crystal- } \\
\text { lite size D } \\
(\mathrm{nm})\end{array}$ & $\begin{array}{l}\text { Lattice } \\
\text { constant } a \\
(\AA)\end{array}$ & $\begin{array}{l}\text { Degree of } \\
\text { crystallinity }\end{array}$ \\
\hline ZnS-Pure & - & 28.83 & 2.13 & 5.357 & 45.9 \\
S1 & 0.025 & 28.86 & 2.27 & 5.352 & 58.1 \\
S2 & 0.05 & 29.01 & 2.26 & 5.325 & 63.0 \\
S3 & 0.075 & 28.93 & 2.27 & 5.339 & 56.8 \\
S4 & 0.1 & 28.77 & 2.35 & 5.372 & 43.9 \\
\hline
\end{tabular}

between the planes (hkl) are calculated using Braggs' law and lattice parameter ' $a$ ' for cubic lattice is determined using:

$a=d_{\mathrm{hkl}} \times \sqrt{h^{2}+k^{2}+l^{2}}$.

From the X-ray diffractogram, we have estimated degree of crystallinity using the ratio of area under crystalline peaks to the total area of crystalline peaks and amorphous regions [26]. The variation of nanocrystallite size, lattice parameter and degree of crystallinity for pure and $\mathrm{NaCMC}$ added $\mathrm{ZnS}$ samples are given in Table 1. Figure 2 depicts the variation of lattice constant and degree of crystallinity with $\mathrm{NaCMC}$ concentration. Lattice parameter is found to decrease with concentration of $\mathrm{NaCMC}$, reaches minimum in the case of $\mathrm{S} 2$,

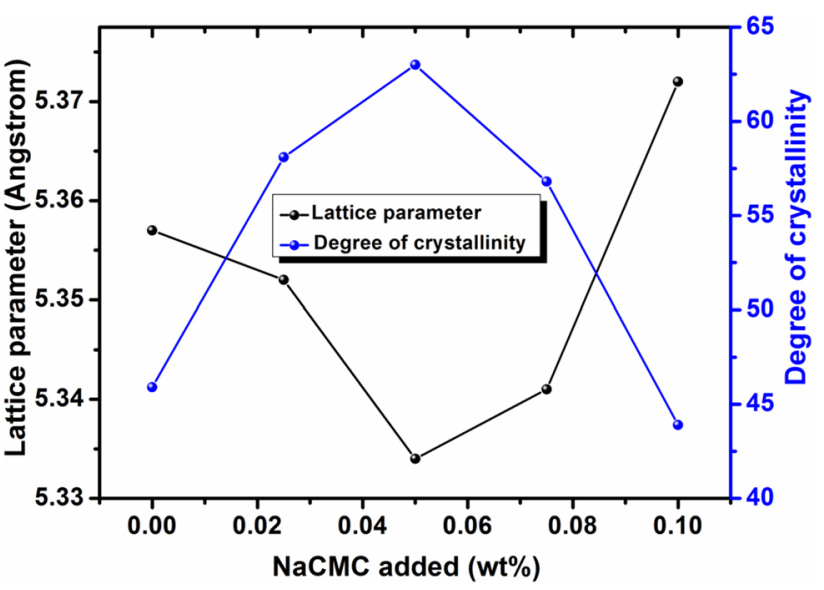

Fig. 2 Variation of lattice parameter and degree of crystallinity with NaCMC addition

and increases thereafter. The crystallinity increases with increase in concentration of NaCMC till $0.05 \%$ (S2) and decreases for further increase in concentration indicating good crystallinity for the sample $\mathrm{S} 2$. The improvement in crystallinity with $\mathrm{NaCMC}$ concentration is attributed to decrease in defects number due to the capping action of $\mathrm{NaCMC}$, resulting in less imperfection in the crystallites. This continues up to $0.05 \mathrm{wt} \%$ concentration of NaCMC and thereafter crystallinity deceases due to aggregation of nanoparticles, seen in TEM micrograph. 


\subsection{UV-Vis spectroscopy}

The plot of absorbance versus wavelength for all samples is shown in Fig. 3.

The excitonic absorption occurs at $\sim 322 \mathrm{~nm}$ for pure $\mathrm{ZnS}$ while it occurs at $332 \mathrm{~nm}$ for NaCMC-capped $\mathrm{ZnS}$ samples. These values are less than that for bulk counterpart which occurs at $337 \mathrm{~nm}$ indicating that the particles are in nanoregime [28]. The appearance of sharp absorption maximum in Fig. 4 shows the monodisperse nature of nanoparticles [29]. With increasing concentration of NaCMC, the position of the absorption maximum remains almost same. This implies that nanoparticle growth is taking place not through Ostwald ripening, for, Ostwald ripening is recognized by the continuation of the excitonic absorption band towards larger wavelengths [30]. Instead, a well-defined absorption maximum occurs repeatedly, implying a discontinuous cluster

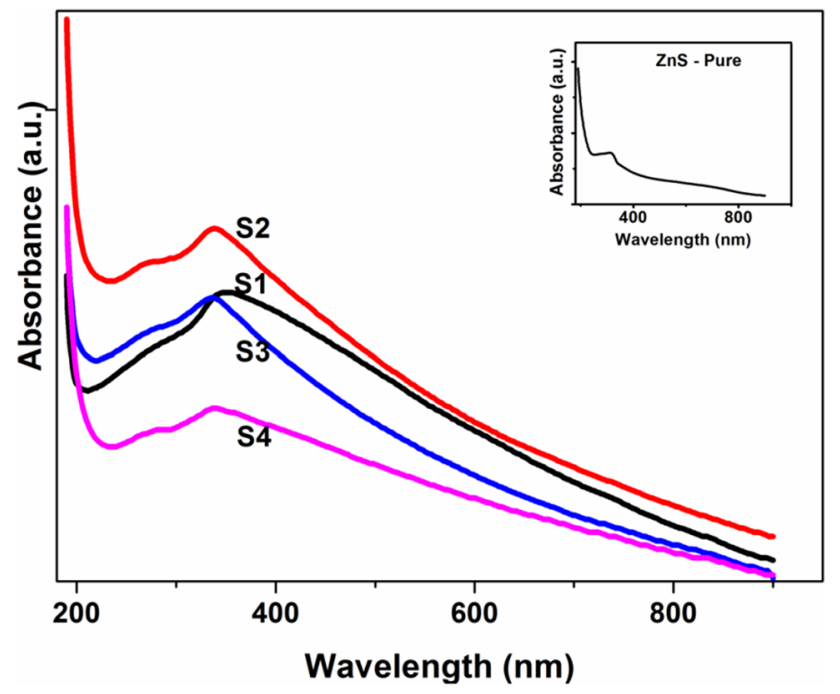

Fig. 3 Absorbance vs wavelength for S1, S2, S3 and S4. Inset is for pure $\mathrm{ZnS}$ sample growth of $\mathrm{ZnS}$ nanocrystals has taken place due to the anionic surfactant NaCMC. From XRD studies also, we observe that the size of coated NPs do not change much for the capped samples except for $0.1 \% \mathrm{NaCMC}$. The UV absorption curves show some absorption in the visible region and this is attributed to defect related states in the band gap [31].

From the studies above, it is apparent that sample S2 is better stabilized among the capped samples and this sample is selected for further analysis. To investigate about morphology, TEM and HRTEM images were taken for $\mathrm{ZnS}$ pure, sample S2 and S4.

\subsection{Electron microscopy}

TEM and HRTEM images of ZnS-pure, samples S2 and S4 are shown.

TEM image shown in Fig. 4a for uncapped $\mathrm{ZnS}$ indicates the formation of solid spheres of size $\sim 100 \mathrm{~nm}$. The bigger size is due to the absence of capping agent. The lattice image (Fig. 4b) for ZnS-pure sample shows crystalline nature which is supported by SAED pattern. The SAED patterns in all cases indicate the polycrystalline behavior with phases (111), (220) and (311) of cubic $\mathrm{ZnS}$.

In the case of sample $\mathrm{S} 2$, formation of spherical nanoclusters of near uniform size is shown by Fig. 5a. Each of these clusters can be seen to contain dispersed primary nanoparticles separated by a thin polymer layer.

In the HRTEM image of the coated nanoparticles (Fig. 5b), an ultrathin film of NaCMC polymer is clearly seen around $\mathrm{ZnS}$ nanoparticles and this film is bound intact to the nanoparticles. Good crystallinity of the sample is exhibited in the lattice image of the micrograph which was revealed by XRD studies also. Discontinuous lattice fringes indicate the polycrystallinity of the sample [32]. The size of NPs is estimated from the HRTEM image (Fig. 5b) the mean size is about $2.6 \mathrm{~nm}$, which is similar to that of XRD results. It has been observed in nanoparticle physics that
Fig. 4 a TEM image for ZnSpure. b HRTEM image with inset showing electron diffraction pattern
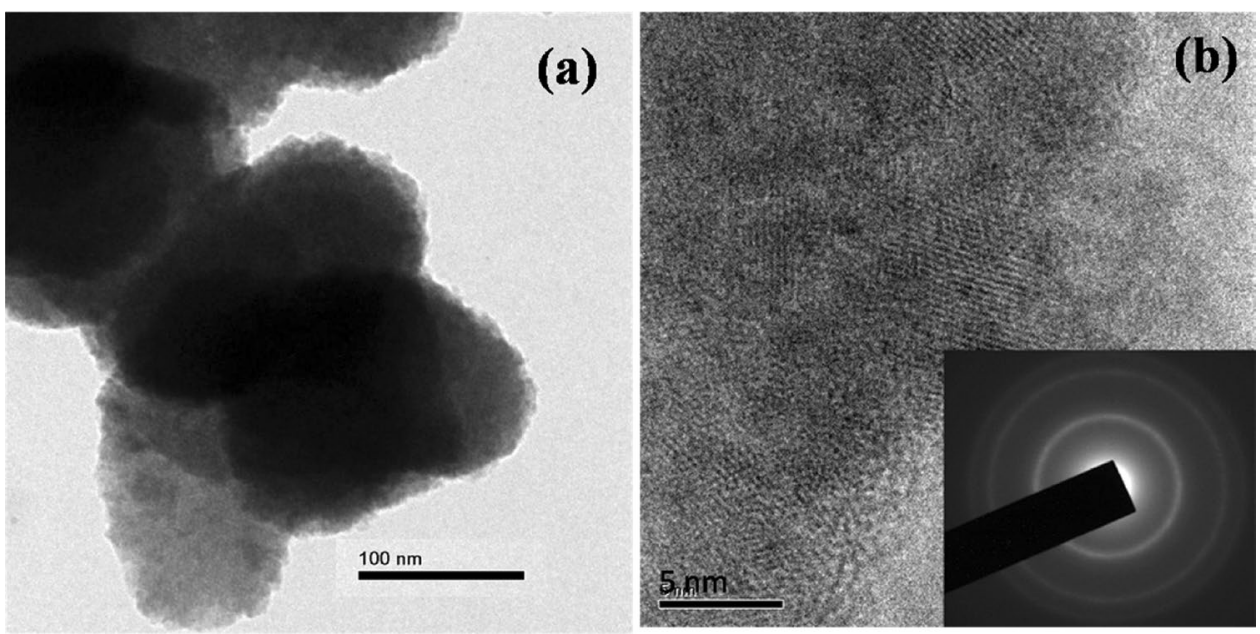
Fig. 5 a Dispersed primary particles in the nanoclusters of sample S2 b Clearly observable lattice fringes and inset of (b) is electron diffraction pattern for $\mathrm{S} 2$
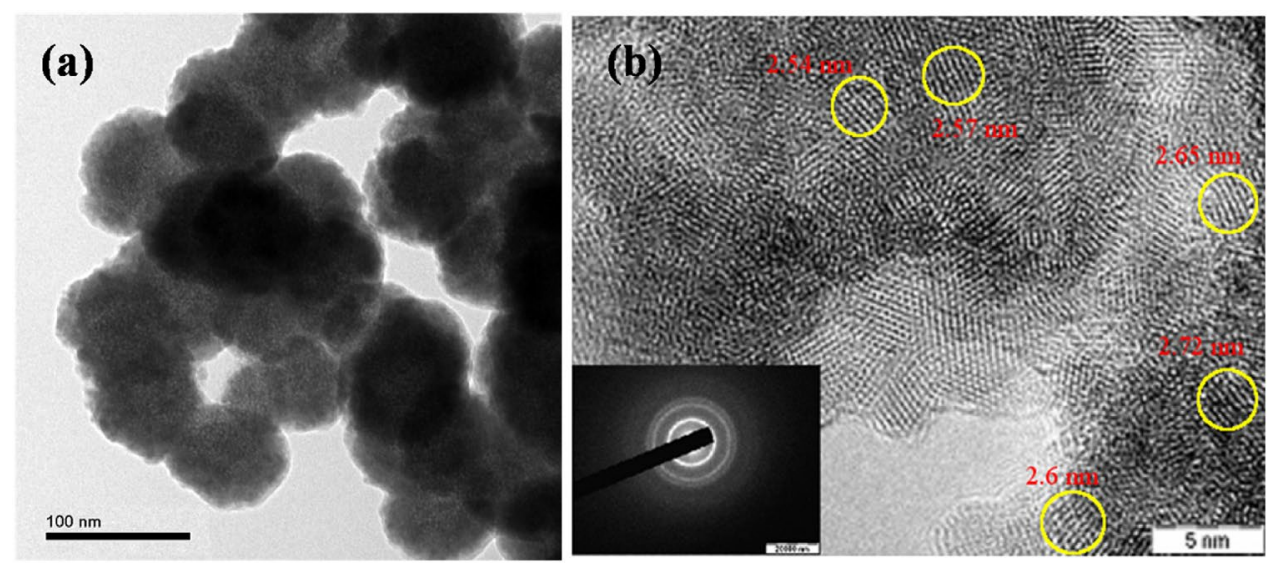

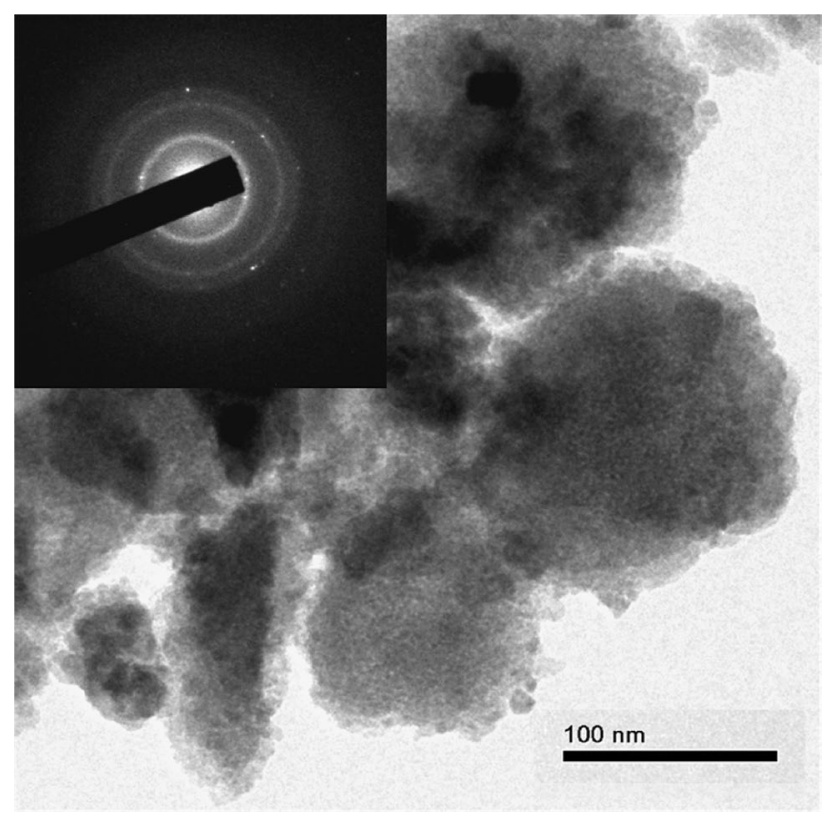

Fig.6 Aggregated NPs of sample S4 and inset is SAED pattern for S4

semiconductor nanocrystals with crystallite size in the range of exciton Bohr radius show size dependent optical properties. The exciton Bohr radius for $\mathrm{ZnS}$ is about $2.5 \mathrm{~nm}$.

Figure 6 shows the TEM image for sample S4. It reveals that, at high concentration of NaCMC, the ZnS NPs formed are aggregated in the matrix of NaCMC. However, the $\mathrm{ZnS}$ NPs formed in this case also exhibited cubic polycrystalline nature indicated by the diffraction pattern.

\subsection{Fourier-transform infrared spectroscopy (FTIR)}

FTIR is based on the principle that the chemical bonds can be excited at frequencies that are typical of the bonds and can provide valuable information about passivation of surface of nanoparticles by the polymer. Figure 7 shows the FTIR spectra for sample S2 and neat NaCMC. The broad

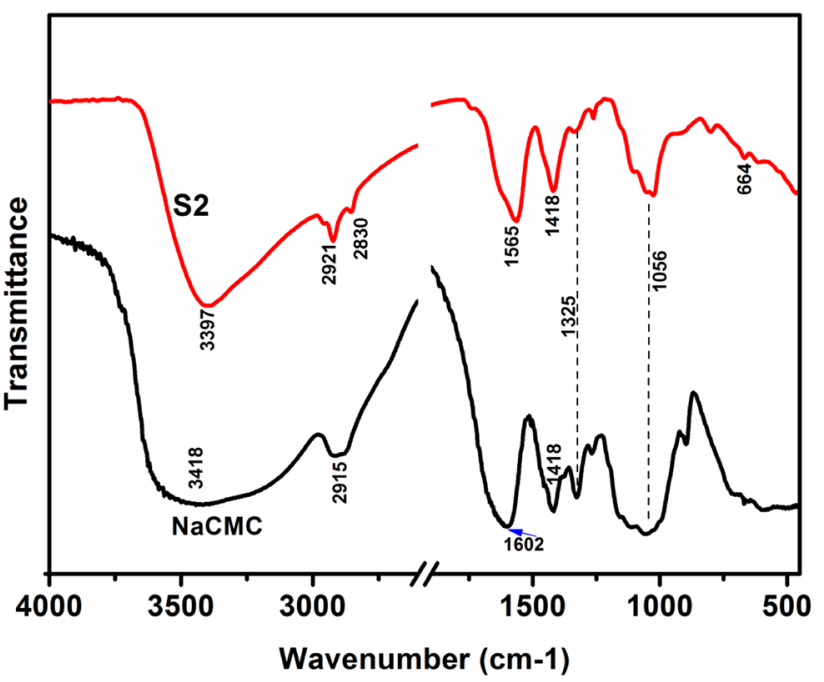

Fig. 7 FTIR spectra of $\mathrm{NaCMC}$ capped $\mathrm{ZnS}$ and pure $\mathrm{NaCMC}$

absorption band at $3418 \mathrm{~cm}^{-1}$ for $\mathrm{NaCMC}$ corresponds to $\mathrm{O}-\mathrm{H}$ stretching and the band at $2915 \mathrm{~cm}^{-1}$ corresponds to $\mathrm{C}-\mathrm{H}$ stretching vibrations. The strong band at $1602 \mathrm{~cm}^{-1}$ and $1418 \mathrm{~cm}^{-1}$ are due to $\mathrm{COO}^{-}$group [33]. The band at $1325 \mathrm{~cm}^{-1}$ is assigned to $-\mathrm{OH}$ bending vibrations [34, 35]. The characteristic $-\mathrm{C}-\mathrm{O}$ stretching on polysachcharide skeleton is indicated by the absorption band at $1056 \mathrm{~cm}^{-1}$. The band at $664 \mathrm{~cm}^{-1}$ is due to $\mathrm{ZnS}$ present in sample S2. The hydroxyl peaks of NaCMC shifted to lower wave number $3397 \mathrm{~cm}^{-1}$ for $\mathrm{S} 2$ indicating a strong interaction between hydroxyl groups of NaCMC and ZnS NPs [36]. The asymmetric and symmetric stretching vibrations at 2921 and $2849 \mathrm{~cm}^{-1}$ are due to $-\mathrm{C}-\mathrm{H}$ vibrations and arise in S2 due to nanostructure formation [17,37]. The band corresponding to $\mathrm{COO}^{-}$shift to $1565 \mathrm{~cm}^{-1}$. The presence of carboxyl and hydroxyl groups in the final $\mathrm{ZnS}-\mathrm{CMC}$ compound is a strong confirmation that there is an interaction between zinc precursor and $\mathrm{NaCMC}$ molecule. 
The growth of ZnS NPs and the capping action of polymer NaCMC may be understood from the chemical reactions involved in the synthesis. During synthesis, the $\mathrm{Zn}^{2+}$ ions formed in aqueous solution of zinc acetate make complexes with $\mathrm{NaCMC}$ added. This solution was microwave (MW) irradiated after the addition of thioacetamide (TA). MWI induces volumetric heating in the material due to inertial, elastic and frictional forces. The power absorbed by the material is represented by [38]:

$P=2 \pi f \varepsilon_{0} \varepsilon_{r}^{\prime} \tan \delta E^{2}$,

where $f$ is frequency $(\mathrm{GHz}), \varepsilon_{0}$ is permittivity of free space, $\varepsilon_{r}^{\prime}$ is relative dielectric constant, $\tan \delta$ is the loss factor and $\mathrm{E}$ is magnitude of internal field. As a result, MW irradiation affects the synthesis process in two ways. First, the polymer NaCMC decomposes during MWI to some extent and produce shorter chains which enable the $\mathrm{Zn}^{2+}$ ions to coordinate with $-\mathrm{OH}$ ligands or make bond with $\mathrm{COO}^{-}$groups [39]. Second, it accelerates the decomposition of TA to provide $\mathrm{S}^{2-}$ ions as:

$$
\begin{aligned}
& \mathrm{CH}_{3} \mathrm{CSNH}_{2}+\mathrm{H}_{2} \mathrm{O} \stackrel{\mathrm{MW} \text { irradiation }}{\longrightarrow} \mathrm{CH}_{3} \mathrm{CONH}_{2}+\mathrm{H}_{2} \mathrm{~S} \\
& \mathrm{H}_{2} \mathrm{~S} \rightarrow 2 \mathrm{H}^{+}+\mathrm{S}^{2-}
\end{aligned}
$$

As soon as $\mathrm{S}^{2-}$ ions become available, reaction between $\mathrm{Zn}^{2+}$ and $\mathrm{S}^{2-}$ ions takes place to form $\mathrm{ZnS}$ nuclei. $\mathrm{ZnS}$ nuclei formed grow into nanoparticles under the combining force between $\mathrm{Zn}^{2+}$ ions and $\mathrm{S}^{2-}$ ions within the cavities bound by the polymer chains [40]. NaCMC being anionic long chain polymer, provides electrostatic as well as steric stabilization. Hence, an increase in crystallite size is observed for NaCMC-capped samples compared to uncapped $\mathrm{ZnS}$. At lower concentration of $\mathrm{NaCMC}$, the availability of fewer $-\mathrm{CH}_{2} \mathrm{COO}^{-}$ligands attached to $\mathrm{NaCMC}$ lead to incomplete coverage of $\mathrm{ZnS}$ NPs. For concentrations of NaCMC like, $0.05 \%$ the NaCMC serves as a shell and final particles formed are nearly spherical, possess uniform size and can disperse well in water [11]. For higher concentrations like $0.1 \%$, the space between polymer chains becomes narrower as a result of increased viscosity [32]. The increased number of polymer chains now provides more carboxyl and hydroxyl linkages to $\mathrm{Zn}^{2+}$ ions leading to the formation of large number of $\mathrm{ZnS}$ nuclei in a small space. Hence, the decrease in crystallinity observed with samples S3 and S4 compared to S2 may be attributed to the aggregation.

\subsection{Photoluminescence (PL) spectroscopy}

The influence of NaCMC capping on the photoluminescence (PL) of ZnS NPs is investigated and PL graphs are shown in Fig. 8. The samples were excited at $250 \mathrm{~nm}$. The

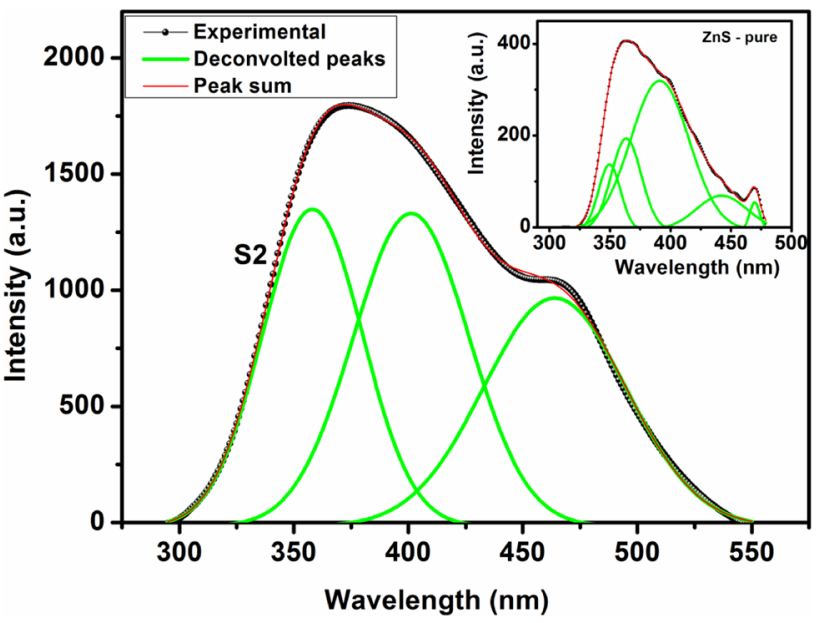

Fig. 8 Photoluminescence spectra for S2 and inset is for pure $\mathrm{ZnS}$

luminescence observed with ZnS- Pure and sample S2 indicate visible emission. Hence emission phenomenon involves localized states in the band gap. The PL spectra obtained are broad and asymmetric, consisting of more than one component. Gaussian curve fitting was applied to deconvolute the PL peaks. The best Gaussian fit gave five peaks for pure $\mathrm{ZnS}$. Weak emission at $350 \mathrm{~nm}$ is attributed to $\mathrm{S}$ interstitials $\left[I_{S}\right]$ and peak at $363 \mathrm{~nm}$ is attributed to $\mathrm{Zn}$ interstitials $\left[\mathrm{I}_{\mathrm{Zn}}\right]$.The strong peak centered at $391 \mathrm{~nm}$ is assigned to the recombination of electrons at the excess $\mathrm{Zn}$ present [41]. Peak at $442 \mathrm{~nm}$ is attributed to transition from surface sulfur vacancy $\left[\mathrm{SV}_{\mathrm{S}}\right]$. Emission peak near $469 \mathrm{~nm}$ is due to internal $S$ vacancy $\left[\mathrm{V}_{\mathrm{S}}\right]$ to internal $\mathrm{Zn}$ vacancy $\left[\mathrm{V}_{\mathrm{Zn}}\right]$ [42].

In the case of NaCMC-capped sample, the peak at $355 \mathrm{~nm}$ is attributed to interstitial $\mathrm{S}\left[\mathrm{I}_{\mathrm{S}}\right]$ ions. As the radius of $\mathrm{S}$ ions is larger than that of $\mathrm{Zn}$ ions, interstitial $\mathrm{S}$ causes greater strain and possess less binding energy. Corresponding energy levels lie close to valence band and energy levels for $\mathrm{Zn}$ interstitials lie close to conduction band. Zn-related emission occurs at $399 \mathrm{~nm}$. Peak near $470 \mathrm{~nm}$ is assigned due to internal $\mathrm{S}$ and $\mathrm{Zn}$ vacancies. Surface sulfur vacancy related emissions are not observed for NaCMC capped sample.

Energy-dispersive $\mathrm{X}$-ray analysis showed that the amount of sulfur is less compared to zinc in the capped as well as uncapped samples which may give rise to sulfur vacancies at the surface causing $\mathrm{Zn}$ dangling bonds and form shallow donor levels. But in the emission spectra of capped sample, no band corresponding to surface sulfur vacancy is found indicating the strong coupling of dangling bonds of $\mathrm{ZnS}$ with NaCMC. As supported by FTIR, there is bonding between $\mathrm{NaCMC}$ and excess $\mathrm{Zn}^{2+}$ ions present on surface of $\mathrm{ZnS}$ nanoparticles.

The important difference between PL spectra of pure ZnS and $\mathrm{S} 2$ is in the number of PL peaks and their intensity. In pure- $\mathrm{ZnS}$, due to surface sulfur and surface zinc related 
5 emission peaks were observed, but on capping, these emissions were absent. The capped $\mathrm{ZnS}$ is having more $\mathrm{PL}$ intensity owing to controlled homogeneous growth of the nanoparticles in solution medium. The higher PL intensity in NaCMC-capped sample is attributed to better passivation of surface-related defects, leading to an increase in electron-hole recombination [43, 44]. The low PL intensity observed with $\mathrm{ZnS}$-Pure is due to the presence of surface defects which cause nonradiative decay.

Schematic of the photoemission in $\mathrm{S} 2$ is represented by Fig. 9.

\subsection{Raman scattering}

Raman spectroscopy is a fast and useful technique to analyze surface properties of nanosized particles. Figure 10 corresponds to the room temperature Raman spectra of sample S2 and neat $\mathrm{NaCMC}$ obtained using excitation source of wavelength $1024 \mathrm{~nm}$. The excitation energy is in off-resonance regime for $\mathrm{ZnS}$. Bands observed for capped $\mathrm{ZnS}$ nanoparticles near $260 \mathrm{~cm}^{-1}$ and $343 \mathrm{~cm}^{-1}$ are assigned to transverse optical (TO) and longitudinal optical (LO) modes, respectively, for cubic phase of $\mathrm{ZnS}$. For bulk $\mathrm{ZnS}$, these bands were reported to occur at $276 \mathrm{~cm}^{-1}$ for TO and $351 \mathrm{~cm}^{-1}$ for LO modes [45].The larger Raman shift from bulk in the present study may be due to the effect of phonon confinement resulting from the small size of particles $(\approx 2.3 \mathrm{~nm})$. Some of the skeletal and carboxylate ion related vibrations due to NaCMC also occur in S2. The assignment of Raman vibrations for neat $\mathrm{NaCMC}$ and $\mathrm{S} 2$ are derived from the literature [46-48] and given in Table 2. The appearance of Raman modes of vibration for NaCMC along with that for $\mathrm{ZnS}$ in sample $\mathrm{S} 2$ indicates the interaction of $\mathrm{NaCMC}$ with ZnS NPs.

There were no Raman bands around $286 \mathrm{~cm}^{-1}$ corresponding to wurtzite phase [45]. This is in accordance

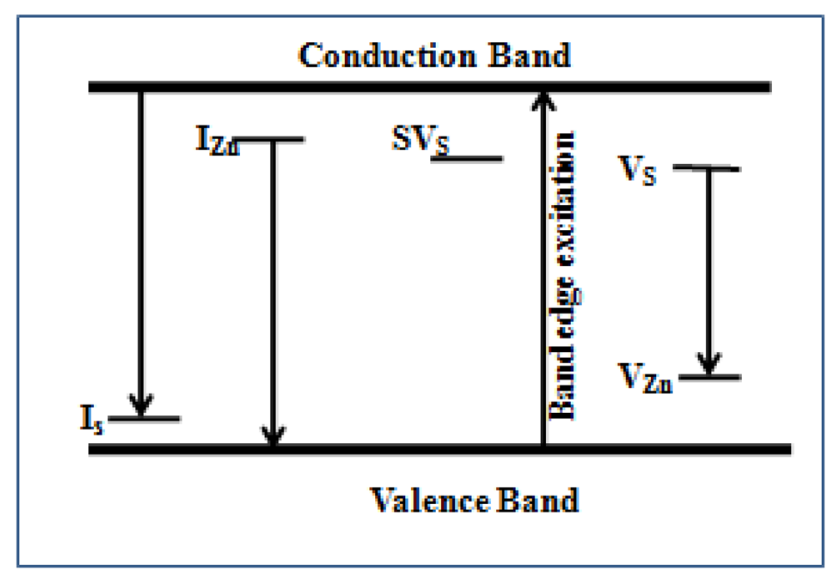

Fig. 9 Schematic of PL emission for S2

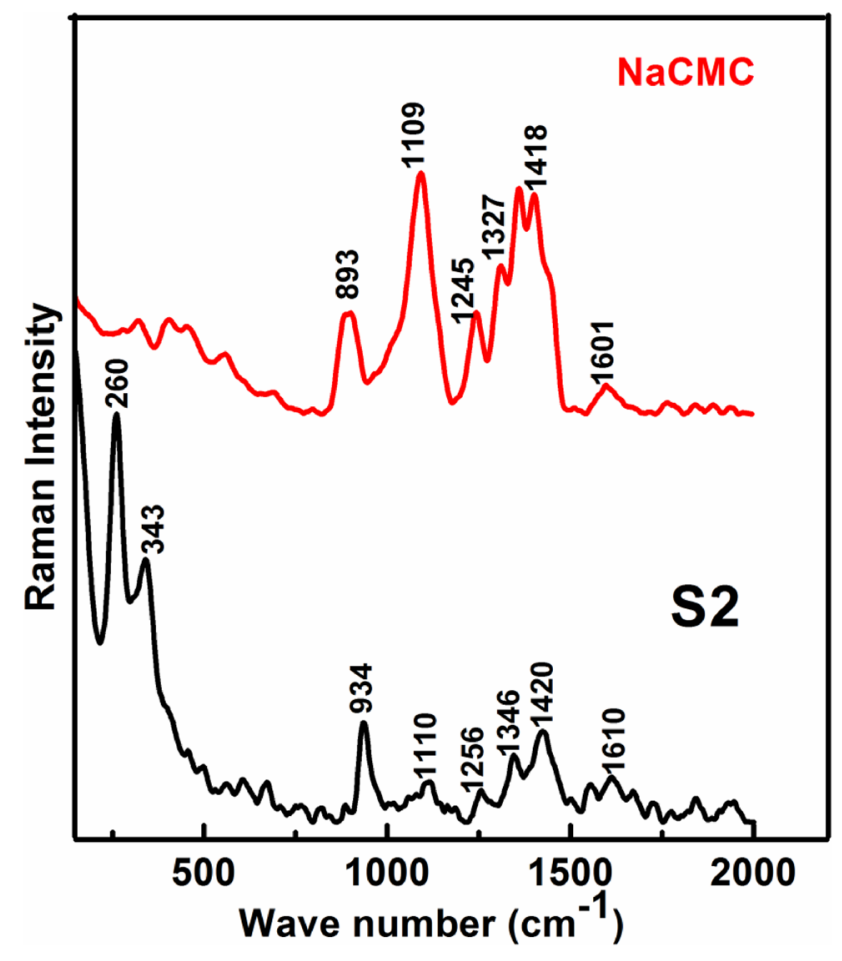

Fig. 10 Raman spectra for $\mathrm{NaCMC}$ and sample S2

with XRD results which show peaks corresponding to cubic $\mathrm{ZnS}$ only.

\subsection{Thermal properties}

Thermo gravimetric analysis (TGA) plays an important role in determining thermal stability of the materials. To understand the thermal behavior of the ZnS-NaCMC composite, TGA were performed for $\mathrm{ZnS}$-pure, sample $\mathrm{S} 2$ and neat NaCMC. TGA curves are shown in Fig. 11. In all curves, the initial loss in weight is due to the loss of adsorbed gases from the surface. For sample S2 and neat $\mathrm{NaCMC}$, the second loss in weight occurs due to the loss of $\mathrm{CO}_{2}$ from the Cellulose. In this temperature range, the decarboxylation of $\mathrm{COO}^{-}$group in $\mathrm{CMC}$ takes place which demonstrates the decomposition of CMC [49]. Neat $\mathrm{NaCMC}$ experienced a $50 \%$ weight loss at a temperature of $\sim 300{ }^{\circ} \mathrm{C}$, whereas for sample S2, it was only $15 \%$ weight loss at temperature $\sim 450{ }^{\circ} \mathrm{C}$. The TGA curve for neat $\mathrm{NaCMC}$ is steep between $250^{\circ} \mathrm{C}$ and $300^{\circ} \mathrm{C}$ while sample $\mathrm{S} 2$ shows broader decomposition temperatures in the range $250^{\circ} \mathrm{C}-450^{\circ} \mathrm{C}$, indicating a better thermal stability of $\mathrm{S} 2$ compared to NaCMC [50]. The drastic decrease in mass for pure $\mathrm{ZnS}$ and sample $\mathrm{S} 2$ beyond $600^{\circ} \mathrm{C}$ indicates the decomposition of $\mathrm{ZnS}$ into its constituents. 
Table 2 Assignment of Raman bands for $\mathrm{NaCMC}$ and $\mathrm{S} 2$

\begin{tabular}{lll}
\hline $\begin{array}{l}\text { Raman peak position in NaCMC } \\
\left(\mathrm{cm}^{-1}\right)\end{array}$ & $\begin{array}{l}\text { Raman peak position in Sample S2 } \\
\left(\mathrm{cm}^{-1}\right)\end{array}$ & Approximate assignment \\
\hline- & 260 & ZnS TO mode \\
- & 343 & ZnS LO mode \\
893 & 934 & Cellulose backbone \\
1109 & 1110 & $-\mathrm{COC}_{\text {glycosidic stretching }}$ \\
1245 & 1256 & $\mathrm{CH}_{2}$ twisting mode \\
1327 & 1346 & $\mathrm{CH}_{2}$ wagging \\
1418 & 1420 & Symmetric stretching of $\mathrm{COO}^{-}$ \\
1601 & 1610 & Asymmetric stretching of $\mathrm{COO}^{-}$ \\
\hline
\end{tabular}

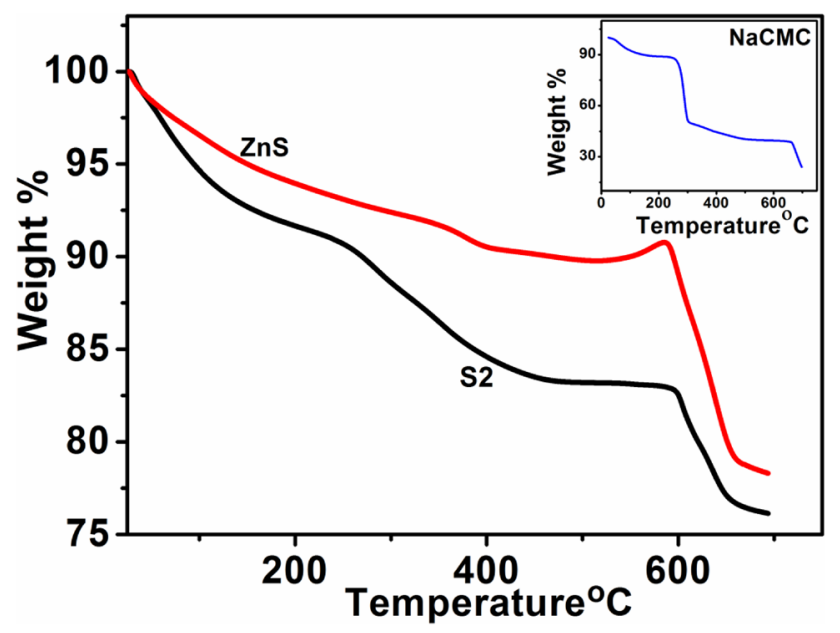

Fig. 11 TGA curves of $\mathrm{ZnS}$-pure, sample $\mathrm{S} 2$ and inset is TGA curve for $\mathrm{NaCMC}$

Some of the properties of the sample $\mathrm{S} 2$ are presented in the following Table 3 along with the results obtained in other published works.

In all, we have seen that, the $\mathrm{ZnS}$ nanoparticles when properly capped with $\mathrm{NaCMC}$, becomes a good light emitter. By studying magnetic nature of these NPs, this work can be extended for targeted drug delivery.

\section{Conclusions}

In summary, microwave assisted synthesis of $\mathrm{NaCMC}$ capped ZnS NPs was carried out by chemical precipitation method. From the studies on structural and optical properties of samples, following conclusions were drawn:

- Powder XRD and TEM studies indicated that the synthesized samples of $\mathrm{ZnS}$ possessed sphalerite structure with average nanocrystallite size less than $3 \mathrm{~nm}$. $\mathrm{NaCMC}$-capped $\mathrm{ZnS}$ showed increase in nanocrystallite size compared to uncapped one. But it did not increase with concentration of $\mathrm{NaCMC}$ which was supported by UV-absorption studies. Blue shift of UV-Vis absorption peaks indicated quantum size effect.

- The surface shallow defect related emissions of $\mathrm{ZnS}$ were quenched with $\mathrm{NaCMC}$ capping. A very good enhancement in photoluminescence intensity was observed with NaCMC-capped sample compared to uncapped $\mathrm{ZnS}$.

- FTIR and Raman studies suggested that capping action of $\mathrm{NaCMC}$ onto $\mathrm{ZnS}$ takes place through the linkages of $-\mathrm{OH}$ and $\mathrm{COO}^{-}$ligands.

- The thermal studies also confirmed the interaction of $\mathrm{NaCMC}$ with $\mathrm{ZnS}$. 
Table 3 Comparison of some physical parameters of $\mathrm{ZnS}$ structures grown by different techniques

\begin{tabular}{|c|c|c|c|c|c|c|}
\hline Ref & Method & Capping agent & Sulfur source & $\begin{array}{l}\text { Crystallite size } \\
\text { from XRD } \\
(\mathrm{nm})\end{array}$ & Strain in crystal & Shape of nanostructure \\
\hline $\begin{array}{l}\text { Present } \\
\text { work S2 } \\
\text {-sample }\end{array}$ & Microwave irradiation & $\begin{array}{l}\text { Sodium carboxy methyl } \\
\text { cellulose }\end{array}$ & Thio acetamide & 2.26 & 0.0612 & Nanospheres \\
\hline \multirow[t]{2}{*}{ [51] } & \multirow[t]{2}{*}{ Chemical precipitation } & \multirow[t]{2}{*}{-} & Thio urea & 4 & - & Star like \\
\hline & & & Sodium sulfide & 4 & - & Star like \\
\hline \multirow[t]{3}{*}{ [52] } & \multirow{3}{*}{$\begin{array}{l}\text { Chemical precipitation } \\
\text { and Chemical bath } \\
\text { deposition }\end{array}$} & \multirow[t]{3}{*}{ Ethylene diamine } & \multirow[t]{3}{*}{ Thioacetamide } & 4.5 & - & No analysis done \\
\hline & & & & 8 & - & $\begin{array}{l}\text { Thin film on Si substrate } \\
\text { Isosceles triangular sur- } \\
\text { face seen in AFM }\end{array}$ \\
\hline & & & & $<4.5$ & - & $\begin{array}{l}\text { Thin film on glass } \\
\text { substrate } \\
\text { Square like surface seen } \\
\text { in AFM }\end{array}$ \\
\hline [53] & $\begin{array}{l}\text { Microwave Assisted } \\
\text { synthesis }\end{array}$ & $\begin{array}{l}\text { Tetrabutyl ammonium } \\
\text { hydroxide }\end{array}$ & Thio urea & 20.7 & 0.0010 & $\begin{array}{l}\text { Irregular spherical } \\
\text { structures }\end{array}$ \\
\hline [23] & $\begin{array}{l}\text { Microwave Assisted } \\
\text { synthesis }\end{array}$ & $\begin{array}{l}\text { Polyvinyl pyrrolidone } \\
\text { (PVP) }\end{array}$ & $\mathrm{Na}_{2} \mathrm{~S}$ & - & - & $\begin{array}{l}\text { Particles with large } \\
\text { aggregation effects }\end{array}$ \\
\hline [54] & Chemical precipitation & L-cysteine & $\mathrm{Na}_{2} \mathrm{~S}$ & 2.10 & - & $\begin{array}{l}\text { Monodispersed particles } \\
\text { with less agglomera- } \\
\text { tion after capping }\end{array}$ \\
\hline
\end{tabular}

Acknowledgements The authors thank Bhandarkars' Arts and Science college, Kundapura for sample preparation facilities, DST PURSE Laboratory, Mangalore University - Mangalore for thermal analysis, DST- SAIF centre, IIT Madras at Chennai for Raman scattering experiments, DST- SAIF centre at Karnatak University-Dharwad for FTIR and photoluminescence measurements and Manipal Academy of Higher Education-Manipal for other characterizations. Author Lalitha Devi B thanks the University Grants Commission, Government of India, for teacher fellowship.

Funding Open access funding provided by Manipal Academy of Higher Education, Manipal.

\section{Compliance with ethical standards}

Conflict of interest The authors declare that they have no conflict of interest.

Open Access This article is licensed under a Creative Commons Attribution 4.0 International License, which permits use, sharing, adaptation, distribution and reproduction in any medium or format, as long as you give appropriate credit to the original author(s) and the source, provide a link to the Creative Commons licence, and indicate if changes were made. The images or other third party material in this article are included in the article's Creative Commons licence, unless indicated otherwise in a credit line to the material. If material is not included in the article's Creative Commons licence and your intended use is not permitted by statutory regulation or exceeds the permitted use, you will need to obtain permission directly from the copyright holder. To view a copy of this licence, visit http://creativecommons.org/licenses/by/4.0/.

\section{References}

1. M. Sabet, M. Salavati-Niasari, E. Esmaeili, Synthesis of zinc sulfide nanostructures with different sulfur sources via mild hydrothermal route: investigation of crystal phase and morphology. J. Inorg. Organomet. Polym. Mater. 26, 738-743 (2016). https ://doi.org/10.1007/s10904-016-0374-y

2. R. Ramachandran, M. Saranya, P. Kollu, B.P.C. Raghupathy, S.K. Jeong, A.N. Grace, Solvothermal synthesis of zinc sulfide decorated graphene $(\mathrm{ZnS} / \mathrm{G})$ nanocomposites for novel supercapacitor electrodes. Electrochim. Acta. 178, 647-657 (2015). https://doi. org/10.1016/j.electacta.2015.08.010

3. R. Hernández Castillo, M. Acosta, I. Riech, G. Santana-Rodríguez, J. Mendez-Gamboa, C. Acosta, M. Zambrano, Study of $\mathrm{ZnS} / \mathrm{CdS}$ structures for solar cells applications. Optik (Stuttg) 148, 95-100 (2017). https://doi.org/10.1016/j.ijleo.2017.09.002

4. S. Anjum, S. Shaheen, M.S. Awan, R. Zia, Effect of various surfactants on optical and electrical properties of $\mathrm{Cu}+2$-doped $\mathrm{ZnS}$ semiconductor nanoparticles. Appl. Phys. A Mater. Sci. Process. (2019). https://doi.org/10.1007/s00339-019-2558-0

5. M.L. Desai, B. Deshmukh, N. Lenka, V. Haran, S. Jha, H. Basu, R.K. Singhal, P.F. Sharma, S.K. Kailasa, K.H. Kim, Influence of doping ion, capping agent and $\mathrm{pH}$ on the fluorescence properties of zinc sulfide quantum dots: Sensing of $\mathrm{Cu} 2+$ and $\mathrm{Hg} 2+$ ions and their biocompatibility with cancer and fungal cells, Spectrochim. Acta Part A Mol. Biomol. Spectrosc. 210, 212-221 (2019). https ://doi.org/10.1016/j.saa.2018.11.027

6. H. Labiadh, K. Lahbib, S. Hidouri, S. Touil, T.B.E.N. Chaabane, Insight of $\mathrm{ZnS}$ nanoparticles contribution in different biological uses. Asian Pac. J. Trop. Med. 9, 757-762 (2016). https://doi. org/10.1016/j.apjtm.2016.06.008

7. C. Ramamoorthy, V. Rajendran, Formation of solid and hollow sphere $\mathrm{ZnS}$ nanoparticles by hydrothermal process and their 
structural, optical and photocatalytic activity. Appl. Phys. A. 124, 500 (2018). https://doi.org/10.1007/s00339-018-1851-7

8. M.S. Rani, N. Dzulkurnain, N.S. Ahmad, Mohamed, , Conductivity and dielectric behavior studies of carboxymethyl cellulose from kenaf bast fiber incorporated with ammonium acetate-BMATFSI biopolymer electrolytes. Int. J. Polym. Anal. Charact 20, 250-260 (2015). https://doi.org/10.1080/1023666X.2015.1013176

9. J.S. Behra, J. Mattsson, O.J. Cayre, E.S.J. Robles, H. Tang, T.N. Hunter, Characterization of sodium carboxymethyl cellulose aqueous solutions to support complex product formulation: a rheology and light scattering study. ACS Appl. Polym. Mater. 1, 344-358 (2019). https://doi.org/10.1021/acsapm.8b00110

10. A.C. De Jesus, S.M. Carvalho, L.C. De, H.S. Mansur, Superabsorbent crosslinked carboxymethyl cellulose-PEG hydrogels for potential wound dressing applications SAP membrane superabsorbent crosslinked PEG-carboxymethyl cellulose tissue repaired hydrogels for potential treatment of wounds. Int. J. Biol. Macromol. (2017). https://doi.org/10.1016/j.ijbiomac.2017.08.124

11. M. Cui, F.J. Wang, Z.Q. Shao, F.S. Lu, W.J. Wang, Influence of DS of CMC on morphology and performance of magnetic microcapsules. Cellulose 18, 1265-1271 (2011). https://doi. org/10.1007/s10570-011-9570-7

12. T. Jiang, J. Li, L. Zhang, B. Wang, J. Zhou, Microwave assisted in situ synthesis of $\mathrm{Ag}-\mathrm{NaCMC}$ films and their reproducible surface-enhanced Raman scattering signals. J. Alloys Compd. 602, 94-100 (2014). https://doi.org/10.1016/j.jallcom.2014.03.020

13. G. Mohammed, A.M. El Sayed, Preparation and characterization of $\mathrm{PbO} /$ carboxymethyl cellulose/polyvinylpyrrolidone nanocomposite films. Polym. Compos. (2017). https://doi.org/10.1002/ pc. 24402

14. P. Kanmani, J.W. Rhim, Properties and characterization of bionanocomposite films prepared with various biopolymers and $\mathrm{ZnO}$ nanoparticles. Carbohydr. Polym. 106, 190-199 (2014). https:// doi.org/10.1016/j.carbpol.2014.02.007

15. C.R. Tang, Z.H. Su, B.G. Lin, H.W. Huang, Y.L. Zeng, S. Li, H. Huang, Y.J. Wang, C.X. Li, G.L. Shen, R.Q. Yu, A novel method for iodate determination using cadmium sulfide quantum dots as fluorescence probes. Anal. Chim. Acta. 678, 203-207 (2010). https://doi.org/10.1016/j.aca.2010.08.034

16. J.F. Luna-Martínez, D.B. Hernández-Uresti, M.E. Reyes-Melo, C.A. Guerrero-Salazar, V.A. González-González, S. SepúlvedaGuzmán, Synthesis and optical characterization of ZnS-sodium carboxymethyl cellulose nanocomposite films. Carbohydr. Polym. 84, 566-570 (2011). https://doi.org/10.1016/j.carbp ol.2010.12.021

17. G. Aguilera, C.C. Berry, R.M. West, E. Gonzalez-Monterrubio, A. Angulo-Molina, Ó. Arias-Carrión, M.Á. Méndez-Rojas, Carboxymethyl cellulose coated magnetic nanoparticles transport across a human lung microvascular endothelial cell model of the blood-brain barrier. Nanoscale Adv. 1, 671-685 (2019). https:// doi.org/10.1039/c8na00010g

18. V.V. Spiridonov, I.G. Panova, L.A. Makarova, M.I. Afanasov, S.B. Zezin, A.V. Sybachin, A.A. Yaroslavov, The one-step synthesis of polymer-based magnetic $\gamma-\mathrm{Fe}_{2} \mathrm{O}_{3}$ /carboxymethyl cellulose nanocomposites. Carbohydr. Polym. 177, 269-274 (2017). https://doi.org/10.1016/j.carbpol.2017.08.126

19. Y. Zhu, F. Chen, Microwave-assisted preparation of inorganic nanostructures in liquid phase. Chem. Rev. (2013). https://doi. org/10.1021/cr400366s

20. S. Lee, D. Song, D. Kim, J. Lee, S. Kim, I.Y. Park, Y.D. Choi, Effects of synthesis temperature on particle size/shape and photoluminescence characteristics of $\mathrm{ZnS}$ : $\mathrm{Cu}$ nanocrystals. Mater. Lett. 58, 342-346 (2004). https://doi.org/10.1016/S0167 $-577 X(03) 00483-X$

21. D.W. Synnott, M.K. Seery, S.J. Hinder, J. Colreavy, S.C. Pillai, Novel microwave assisted synthesis of $\mathrm{ZnS}$ nanomaterials. Nanotechnology. 24, 045704 (2013). https:// doi.org/10.1088/0957-4484/24/4/045704

22. X. Liu, Z. Li, C. Zhao, W. Zhao, J. Yang, Y. Wang, F. Li, Facile synthesis of core-shell $\mathrm{CuO} / \mathrm{Ag}$ nanowires with enhanced photocatalytic and enhancement in photocurrent. J. Colloid Interface Sci. 419, 9-16 (2014). https://doi.org/10.1016/j. jcis.2013.12.042

23. K. Patel, M.P.D.S.H. Chaki, Effect of Ag on structural, optical and luminescence properties of $\mathrm{ZnS}$ nanoparticles synthesized by microwave-assisted chemical route. Appl. Phys. A. 123, 367 (2017). https://doi.org/10.1007/s00339-017-0980-8

24. X. Tian, J. Wen, S. Wang, J. Hu, J. Li, H. Peng, Starch-assisted synthesis and optical properties of $\mathrm{ZnS}$ nanoparticles. Mater. Res. Bull. 77, 279-283 (2016). https://doi.org/10.1016/j.materresbu 11.2016 .01 .046

25. G. Murugadoss, Synthesis and optical characterization of PVP and SHMP-encapsulated Mn 2-doped $\mathrm{ZnS}$ nanocrystals. J. Lumin. 130, 2207-2214 (2010). https://doi.org/10.1016/j.jlumi n.2010.06.021

26. P. Bansal, M. Hall, M.J. Realff, J.H. Lee, A.S. Bommarius, Multivariate statistical analysis of X-ray data from cellulose: A new method to determine degree of crystallinity and predict hydrolysis rates. Bioresour. Technol. 101, 4461-4471 (2010). https://doi. org/10.1016/j.biortech.2010.01.068

27. P. Muhammed Shafi, A. Chandra Bose, Impact of crystalline defects and size on X-ray line broadening: A phenomenological approach for tetragonal SnO2 nanocrystals. AIP Adv. 5, 057137 (2015). https://doi.org/10.1063/1.4921452

28. W. Sang, Y. Qian, J. Min, D. Li, L. Wang, Microstructural and optical properties of $\mathrm{ZnS}: \mathrm{Cu}$ nanocrystals prepared by an ion complex transformation method. Solid. State. Communic. 121, 475-478 (2002). https://doi.org/10.1016/S0038-1098(01)00518 $-\mathrm{X}$

29. A.K. Kole, P. Kumbhakar, U. Chatterjee, Observation of nonlinear absorption and visible photoluminescence emission in chemically synthesized $\mathrm{Cu} 2+$ doped $\mathrm{ZnS}$ nanoparticles Observation of nonlinear absorption and visible photoluminescence emission in chemically synthesized $\mathrm{Cu} 21$ doped $\mathrm{ZnS}$ nanoparticles. Appl. Phys. Lett. 100, 013103 (2012). https://doi.org/10.1063/1.36743 07

30. S. Wageh, Z. Su, X. Xu-rong, Growth and optical properties of colloidal ZnS nanoparticles. J. Crystal Growth 255, 332-337 (2003). https://doi.org/10.1016/S0022-0248(03)01258-2

31. J. Zhang, S. Liu, J. Yu, M. Jaroniec, A simple cation exchange approach to Bi-doped $\mathrm{ZnS}$ hollow spheres with enhanced UV and visible-light photocatalytic $\mathrm{H}_{2}$-production activity. J. Mater. Chem. 21, 14655 (2011). https://doi.org/10.1039/c1jm12596f

32. J. Li, K. Inukai, Y. Takahashi, A. Tsuruta, W. Shin, Effect of PVP on the synthesis of high-dispersion core-shell barium-titanatepolyvinylpyrrolidone nanoparticles. J. Asian Ceram. Soc. 5, 216-225 (2017). https://doi.org/10.1016/j.jascer.2017.05.001

33. M.A. Martínez-Rodríguez, M.A. Garza-Navarro, I.E. MorenoCortez, R. Lucio-Porto, V.A. González-González, Silver/polysaccharide-based nanofibrous materials synthesized from green chemistry approach. Carbohydr. Polym. 136, 46-53 (2016). https ://doi.org/10.1016/j.carbpol.2015.09.014

34. L.Y. Wang, M.J. Wang, Removal of heavy metal ions by Poly(vinyl alcohol) and carboxymethyl cellulose composite hydrogels prepared by a freeze-thaw method. ACS Sustain. Chem. Eng. 4, 2830-2837 (2016). https://doi.org/10.1021/acssuschem eng.6b00336

35. D. de Britto, O.B.G. Assis, Thermal degradation of carboxymethylcellulose in different salty forms. Thermochim. Acta. 494, 115-122 (2009). https://doi.org/10.1016/j.tca.2009.04.028

36. J. Zeng, S. Liu, J. Cai, L. Zhang, TiO2 immobilized in cellulose matrix for photocatalytic degradation of phenol under weak UV 
light irradiation. J. Phys. Chem. C. 114, 7806-7811 (2010). https ://doi.org/10.1021/jp1005617

37. B.S.R. Devi, R. Raveendran, A.V. Vaidyan, Synthesis and characterization of Mn $2+$-doped $\mathrm{ZnS}$ nanoparticles. Pramana -J. Phys 68, 679-687 (2007)

38. S. Das, A.K. Mukhopadhyay, S. Datta, D. Basu, Prospects of microwave processing an overview. Bull Mater Sci. 31, 943-956 (2008). https://doi.org/10.1007/s12034-008-0150-x

39. N. Rangelova, L. Aleksandrov, T. Angelova, N. Georgieva, R. Müller, Preparation and characterization of $\mathrm{SiO} 2 / \mathrm{CMC} / \mathrm{Ag}$ hybrids with antibacterial properties. Carbohydr. Polym. 101, 1166-1175 (2014). https://doi.org/10.1016/j.carbpol.2013.10.041

40. Z. Zhou, D. He, W. Xu, F. Ren, Y. Qian, Preparing ZnS nanoparticles on the surface of carboxylic poly(vinyl alcohol) nanofibers. Mater. Lett. 61, 4500-4503 (2007). https://doi.org/10.1016/j.matle t.2007.02.041

41. N. Kumbhojkar, V.V. Nikesh, A. Kshirsagar, S. Mahamuni, N. Kumbhojkar, V.V. Nikesh, A. Kshirsagar, Photophysical properties of $\mathrm{ZnS}$ nanoclusters Photophysical properties of ZnS nanoclusters. J. Appl. Phys. 88, 6260 (2000). https://doi. org/10.1063/1.1321027

42. M. Sookhakian, Y.M. Amin, W.J. Basirun, M.T. Tajabadi, N. Kamarulzaman, Synthesis, structural, and optical properties of type-II ZnO - ZnS core - shell nanostructure. J. Lumin. 145, 244-252 (2014). https://doi.org/10.1016/j.jlumin.2013.07.032

43. S.J. Rosenthal, J.C. Chang, O. Kovtun, J.R. McBride, I.D. Tomlinson, Biocompatible quantum dots for biological applications. Chem. Biol. 18, 10-24 (2011). https://doi.org/10.1016/j.chemb iol.2010.11.013

44. M. Taherian, A.A. Sabbagh Alvani, M.A. Shokrgozar, R. Salimi, S. Moosakhani, H. Sameie, F. Tabatabaee, Surface-treated biocompatible $\mathrm{ZnS}$ quantum dots: Synthesis, photo-physical and microstructural properties. Electron. Mater. Lett. 10, 393-400 (2014). https://doi.org/10.1007/s13391-013-3211-2

45. O. Brafman, S.S. Mitra, Raman effect in wurtzite- and zincblende-type ZnS single crystals. Phys. Rev. 171, 931-934 (1968). https://doi.org/10.1103/PhysRev.171.931

46. G. Socrates, in Biological Molecules - Macromolecules, ed. By Socretes, (John Wiley \& Sons Ltd, England 2004) p. 329-330. https://doi.org/10.1002/jrs.1238.
47. P.J. Larkin, "IR and Raman Spectroscopy - Principles and Spectral Interpretation," (Elsevier, Oxford, 2011) pp.135-176 https://doi. org/10.1016/b978-0-12-386984-5.10001-1.

48. J. Blackwell, P.D. Vasko, J.L. Koenig, Infrared and raman spectra of the cellulose from the cell wall of valonia ventricosa infrared and raman spectra of the cellulose from the cell wall of valonia ventricosa. J. Appl. Phys. 41, 4375 (2011). https://doi. org $/ 10.1063 / 1.1658470$

49. B. Sivakumar, R.G. Aswathy, Y. Nagaoka, M. Suzuki, T. Fukuda, Y. Yoshida, T. Maekawa, D.N. Sakthikumar, Multifunctional carboxymethyl cellulose-based magnetic nanovector as a theragnostic system for folate receptor targeted chemotherapy Imaging, and Hyperthermia against Cancer. Langmuir 29, 3453-3466 (2013). https://doi.org/10.1021/la305048m

50. M.N. Nadagouda, R.S. Varma, Synthesis of thermally stable carboxymethyl cellulose / metal biodegradable nanocomposites for potential biological applications. Biomacromol 8, 2762-2767 (2007). https://doi.org/10.1021/bm700446p

51. K. Hedayati, A. Zendehnam, F. Hassanpour, Fabrication and characterization of zinc sulfide nanoparticles and nanocomposites prepared via a simple chemical precipitation method. J Nanostruct. 6, 207-212 (2016). https://doi.org/10.7508/JNS.2016.03.005

52. G. Nabiyouni, R. Sahraei, M. Toghiany, M.H.M. Ara, K. Hedayati, Preparation and characterization of nanostructured $\mathrm{ZnS}$ thin films grown on glass and $\mathrm{N}$-type $\mathrm{Si}$ substrates using a new chemical bath deposition technique. Rev. Adv. Mater. Sci. 27, 52-57 (2011)

53. F.A. La Porta, J. Andrés, M.S. Li, J.R. Sambrano, J.A. Varela, E. Longo, Zinc blende versus wurtzite $\mathrm{ZnS}$ nanoparticles: control of the phase and optical properties by tetrabutylammonium hydroxide. Phys. Chem. Chem. Phys. 16, 20127-37 (2014). https://doi. org/10.1039/c4cp02611j

54. S. Kumar, M. Singhal, J.K. Sharma, Functionalization and characterization of $\mathrm{ZnS}$ quantum dots using biocompatible 1-cysteine. J. Mater. Sci. Mater. Electron. 24, 3875-3880 (2013). https://doi. org/10.1007/s10854-013-1332-x

Publisher's Note Springer Nature remains neutral with regard to jurisdictional claims in published maps and institutional affiliations. 